\title{
Proposal for Improved External Parking Layout of the Organization
}

\author{
Andréa de Oliveira Teixeira ${ }^{1}$, Lecilda Oliveira Batista ${ }^{1}$, Sabrina Albuquerque de Oliveira ${ }^{1}$, Jandecy Cabral Leite $^{2}$ \\ ${ }^{1,2}$ Centro Universitário do Norte - UNINORTE. Av. Joaquim Nabuco, 1469, Centro Manaus-Amazonas-Brasil. CEP: 69005-290. \\ Fone: +55 (92) 3212-5000. (andrea_o_teixeira@hotmail.com, lecildaa@hotmail.com, sabri10_albq@hotmail.com, \\ jandecycabral@hotmail.com)
}

\begin{abstract}
In a dynamic competitive environment, parking is of paramount importance to ensure customer convenience, comfort and safety which enables the organization's success in a long-term business relationship. In this perspective, this article aims to show the study to improve and optimize the layout of the parking lot outside the company JB Scaffolding. The research methodology is characterized as descriptive, data collection on the situation of the organization under study with a quantitative approach type. Were used as instruments of research structured questionnaire with open and closed questions, direct observation, document analysis and photographic record. The results show that parking is critical to retaining customers and ensure competitiveness in the market providing consumers part to increased demand organization and demand for their services and consequently greater efficiency and reliability.
\end{abstract}

Keywords: Improved parking, layout and optimization, J.B Andaimes.

\section{Proposta de Melhoria no Layout do Estacionamento Externo da Organização}

\section{RESUMO}

Em um ambiente dinâmico de competitividade, o estacionamento é de suma importância para garantir ao cliente comodidade, conforto e segurança o qual possibilita o sucesso da organização em um relacionamento comercial em longo prazo. Nesta perspectiva, esse artigo objetiva mostrar o estudo de melhoria e otimização do layout externo do estacionamento da empresa J.B Andaimes. A metodologia da pesquisa caracteriza-se como descritiva, do tipo levantamento de dados da situação da organização em estudo com abordagem quantitativa. Utilizou-se como instrumentos de pesquisa questionários estruturados com perguntas abertas e fechadas, observação direta, análise documental e registro fotográfico. Os resultados mostram que o estacionamento é peça fundamental para reter clientes e garantir competitividade no mercado consumidor proporcionando a organização aumento de demanda e procura pelos serviços prestados e consequentemente maiores rentabilidade e confiabilidade.

Palavras Chaves: Melhoria do estacionamento, layout e otimização, J.B Andaimes.

\section{INTRODUÇÃO}

A concorrência e o aumento da carência de produtos e serviços no âmbito da edificação civil tem tornado complexo a manutenção do movimento econômico da corporação. Nesse sentido a necessidade de consumo faz com que o automóvel se tornasse o produto símbolo do sistema produtivo [1]. Seguindo essa linha de entendimento a agrupamento de empregos, tarefas comerciais e serviços aumentam e a taxa de urbanização acelera, ou seja, a cidade se desenvolve [2].

No atual cenário, a disponibilidade do estacionamento por parte das instituições vem sendo cada vez mais uma exigência do mercado consumidor para que seja inclusa na política empresarial melhoria e otimização do layout externo do estacionamento como instrumento de bem-estar e segurança.

O objetivo desta pesquisa é mostrar como a falta de um estacionamento pode ocasionar riscos para a organização. Desse modo, quando a pergunta é: qual a afinidade entre a expectativa dos clientes pelos serviços prestados e o que a lealdade (concorrência) pode ocasionar? Ressaltam que esta relação não tem a mesma dimensão, e quanto maior a satisfação, maior a manutenção (lealdade) de clientes e, quanto maior o ambiente de competição, maior a necessidade de se alcançar índices superiores de satisfação do cliente [3]. Ou seja, subentende-se que lealdade está associada com a competitividade do ramo de negócio com a aprovação dos stakeholders. 
O layout do estacionamento é de suma importância para a empresa, pois retém clientes e garante competividade no mercado consumidor.

A JB Andaimes há 20 anos atua no mercado com locação de andaimes e tubulações na extensão de edificação civil. E nos últimos anos, esse setor alavancou significativamente na capital e no Estado do Amazonas, conforme o acréscimo de edificações de prédios, centros comerciais, indústrias, etc, o que eleva a procura por esses produtos e serviços e consequentemente, estacionar tornou-se um problema para os clientes. No trânsito está implícita uma disputa pelo espaço: pedestres, mercantes e condutores pleiteiam espaços ao longo da via. O comerciante almeja o máximo de acessibilidade para seu negócio e isto requer estacionamento adequado [4]. O número de veículo em circulação está aumentando rapidamente, e isso pode ser comparado ao aumento da população, aumento do poder aquisitivo e o crescimento da atividade comercial [5].

Devido à problemática relacionada à alocação de veículos, levantou-se a questão: Como melhorar o layout do estacionamento externo da organização? Com o intuito de responder esse quesito, foi proposta a melhoria no layout do estacionamento da empresa, o qual deverá contribuir para o desempenho da instituição como um todo.

\section{REVISÃO BIBLIOGRÁFICA}

\section{II.1 LAYOUT}

Layout ou arranjo físico é a disposição da área destinada aos elementos fixos ou de difícil movimentação que arrumam um espaço físico arquitetado ou ajustado para abrigar, de modo pertinente, as diversas tarefas humanas. Dessa forma, layout corresponde ao arranjo dos diversos postos de trabalho nos espaços existentes na organização, envolvendo, além da preocupação de melhor adaptar as pessoas ao ambiente de trabalho, segundo a natureza da atividade desempenhada, a arrumação dos móveis, maquinas, equipamentos e matérias-primas [6]. Para ressaltar essa teoria, o layout pode ser definido como um esboço da organização administrado de modo a adequar cada área ao local mais apropriado e com a finalidade de racionalizar recursos, processos, movimentação de pessoas e para aperfeiçoar as condições de trabalho dos funcionários [7].

\section{II.2. TIPOS DE LAYOUT}

Há diversos modelos de layout no ambiente organizacional, contudo, [8] cita quatro tipos de arranjo físico: arranjo posicional ou fixo funcional ou processo, linear ou produtos e celular:

- Layout posicional ou fixo é à disposição de instrumentos e equipamentos subordinados a serviços com difícil locomoção, porém o mesmo fica parado e a circulação fica por conta de quem vai manuseá-lo. Assim sendo, fixo, em que as pessoas, com suas máquinas e equipamentos, se locomovem entre os diversos os locais de trabalho, mas o produto fica parado [9].

- Layout por processo ou funcional é a arrumação do espaço onde as máquinas ficam ajuntadas conforme a atividade a ser desempenhadas. Seguindo essa mesma lógica de pensamento [6] afirma que as máquinas são agrupadas de acordo com a natureza da operação que é executada.

- Layout linear ou produto são os meios produtivos convertedores situados linearmente, conforme a melhor condição dos elementos, os quais estão sendo transformado. Layout de produto caracteriza-se pela entrada de matéria-prima em uma das extremidades da linha de produção e pela saída do produto acabado em outro extremo [9].

- Layout de estacionamento é a arrumação da área externa de modo a aplicar da melhor forma aceitável o espaço destinado à acomodação de veículos. Assim o melhor layout de estacionamento depende, principalmente, das características da área disponível, da facilidade de circulação, do tipo de estacionamento (curta ou longa duração) e do tipo de via [11].

\section{II.3. ETAPAS DE UM PROJETO DE LAYOUT}

As fases de um desenho de layout são critérios uniformizados para ponderar uma determinada dificuldade. A norma adotada envolve: levantamento de dados, análise do levantamento, plano da solução do problema, crítica do plano, implementação e controle dos resultados.

Nessa dinâmica, na primeira fase, o pesquisador tem a obrigação de se empenhar a conhecer a natureza da empresa em estudo e escolher quais técnicas utilizar; após os dados colhidos será realizado um julgamento minucioso dessas informações; assim de posse de todo esse aparato começa-se a traçar a decisão do problema; diante da proposta elaborada e analisada criteriosamente, o pesquisador faz uma demonstração da atual proposta do novo layout a seu cliente para futura implementação; depois de feito os ajustes com o cliente e aprovado faz-se a implantação do projeto e logo em seguida, o pesquisador por um período curto de tempo, faz o acompanhamento para averiguar se a solução proposta está de concordata com o esquematizado. Para analisar uma disposição física de uma organização se faz necessário um levantamento do estado atual, para que se possa chegar aos objetivos desejados. O desenvolvimento do estudo de arranjo físico, o analista de sistemas, organização e métodos pode seguir as seguintes etapas [9]:

- Levantamento: fase em que o analista ou o grupo responsável pelo estudo do layout deve familiarizar-se com o plano de organização e os principais procedimentos adotados;

- Crítica do levantamento: fase em que o grupo responsável pelo projeto de layout deve examinar os principais problemas para a execução dos fins visados, dando especial atenção as diferenças existentes entre o que está prescrito na documentação normativa 
Andréa de Oliveira Teixeira, et al / ITEGAM-JETIA Vol.02, Nº6, pp.105-110. Junho, 2016.

da empresa e as técnicas e procedimentos de trabalho realmente encontrados na prática;

- Planejamento da solução: é imprescindível, nesta fase, que os processos e métodos de trabalho, de início, sejam racionalizados e a intervenção planejada da forma mais eficaz possível, sendo esta uma responsabilidade da própria equipe que projeta o novo layout, partindo-se do pressuposto principal de que a cúpula da organização aprovou o desenvolvimento do projeto;

- Crítica do planejamento: fase em que encontradas as soluções julgadas, estas deverão ser objetos de negociações com os usuários do novo layout;

- Implantação: após escolha e aprovação dos usuários, deve ser planejada a implantação da saída que melhor atenda os interesses da organização;

- Controle dos resultados: pequeno período em que a equipe deve acompanhar a mudança, a fim de verificar se a solução foi a melhor ou se ainda há necessidade de pequenas adaptações.

\section{MATERIAIS E MÉTODOS}

É o conjunto de todos os meios e procedimentos empregados para a coleta de dados referente a um tema proposto. O método, enquanto processo lógico e técnico, efetivamente conduz a um resultado que pode ser considerado dentro dos parâmetros do científico, mas toda a pesquisa envolve pressupostos epistemológicos, teóricos e éticos, dependendo do objeto a ser pesquisado, pode-se utilizar a pesquisa experimental, bibliográfica e documental ou uma combinação entre elas e outros recursos metodológicos [12].

O método utilizado no levantamento de dados foi constituído por pesquisas bibliográficas, de campo e documental sendo elaborada em três etapas, aplicada aos três níveis hierárquicos: Na primeira fase utilizou-se como fontes: livros, artigos e sites especializados; na segunda fase foram aplicadas as seguintes ferramentas: entrevistas, registros fotográficos, questionários estruturados com perguntas abertas e fechadas e check-list de observação direta e na terceira fase foram disponibilizados informações para a coleta documental e confirmação de dados.

Após os dados coletados, estes foram analisados de maneira sistemática, tais como: seleção, codificação e tabulação. $\mathrm{Na}$ seleção foi concretizado um julgamento detalhado de todo material coletado e submetido a uma análise crítica a fim de averiguar possíveis falhas ou erros, os quais pudessem depreciar o resultado da pesquisa. Na codificação os dados foram separados e distribuídos de acordo com sua categoria e transformados em qualitativos e quantitativos. $\mathrm{Na}$ tabulação os dados foram comprovados em gráficos, quadros e tabelas para melhor abrangência das informações apresentadas. Os métodos de procedimentos constituem etapas mais concretas da investigação, com a finalidade mais restrita em termos de explicação geral dos fenômenos menos abstratos. Implicam uma atitude real em semelhança ao acontecimento e estão restringidas a um comando privado [13].

A metodologia de investigação utilizada foi descritiva, do tipo classificação de dados da situação da organização em estudo com enfoque quantitativo. O estudo em questão levantou informações sobre um lugar apropriado para o estacionamento, movimentação de veículos tanto dos funcionários quanto dos clientes, o qual venha consentir as perspectivas de todos os envolvidos. Foi também atingida uma análise literária para obter o fundamento teórico e assim dissertar sobre o contexto em questão, citando autores, os quais relatam informações que auxiliam a dirigir a compreensão da dificuldade da melhor forma aceitável, com a finalidade de adquirir a solução mais adequada, a qual atenda às necessidades da organização.

\section{RESULTADOS E DISCUSSÕES}

A empresa J.B. ANDAIMES - Locadora de equipamentos para Construção Civil Ltda. - ME, caracteriza-se por uma organização LTDA e familiar. Possui um galpão com uma área medindo $5.000 \mathrm{~m}^{2}$, onde funciona o estoque dos equipamentos e a sua manutenção, com competência de atender a demanda dos seus clientes, pois a empresa fornece equipamentos para as principais obras de Manaus nos últimos anos. A J.B Andaimes iniciou suas atividades comerciais em 1993, foi registrada na JUCEA em dezembro de 2001, tendo 20 anos no mercado de aluguel de equipamentos para a construção civil. Com relação aos produtos, os quais são bens tangíveis oferecidos ao mercado para obtenção de renda à empresa. Um produto é qualquer oferta que possa satisfazer a uma necessidade ou a um desejo [14].

A figura 1 mostra os produtos da empresa J.B Andaimes os quais são: Andaimes Fachadeiros, Tubular (Mecanfix), Tubo Equipado, Multidirecional Mecanflex e Escoras Metálicas Mecanor e Torre Modular, fabricados pela MECAN.
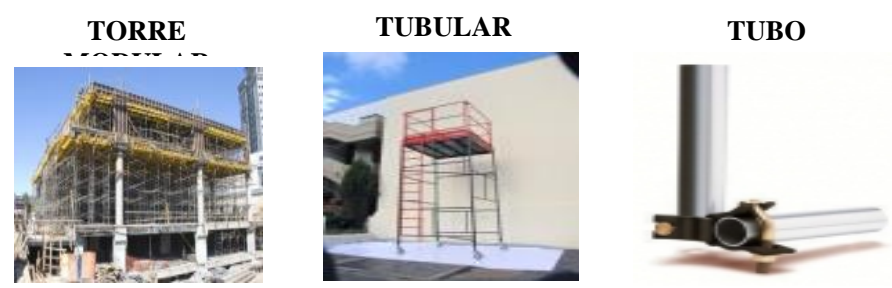

\section{ESCORA}
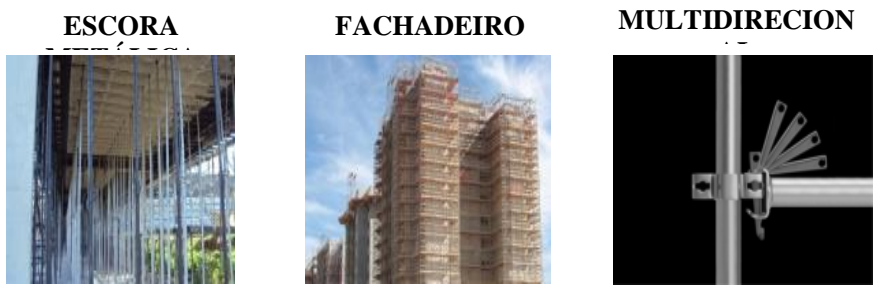

Figura 1- Produtos da Empresa J.B Andaimes (AM).

Fonte: Autores, (2016). 
Com relação ao serviço é um bem intangível que compreende atividades, benefícios ou geração de satisfação oferecido na venda e que resultam não na propriedade de algo. Definem serviços como qualquer ato ou desempenho, essencialmente intangível, que uma parte pode oferecer à outra $\mathrm{e}$ que não resulta na propriedade de nada [15]. Resultando em um produto que não se pode ver ou tocar, mas que pode ser executado de acordo com as exigências de seus clientes, priorizando a qualidade de como está sendo realizado.

No entanto, o serviço da J.B Andaimes é a locação de andaimes que a empresa oferece para aluguel em canteiro de obras ou em lugares diversos.

Os serviços são atividades econômicas oferecidas por uma parte à outra, considerando frequentemente desempenhos com base em período de tempo para provocar resultados desejados nos próprios usuários, em objetos ou em outros bens pelos quais os compradores são responsáveis [16].

A empresa tem em seu quadro ativo 39 colaboradores, os quais são enquadrados de acordo com a CLT - Consolidação das Leis Trabalhistas, distribuindo em vários cargos na organização. Com relação ao quadro funcional, consiste em dividir o trabalho de maneira que cada homem, desde o assistente até o superintendente, tenha de executar a menor variedade possível de funções. Sempre que possível, o trabalho de cada homem devera limitar-se a exceção de uma única função [17].

A figura 2 mostra que a organização tem uma maior abundância de empregados do sexo masculino, o equivalente a $74,36 \%$ da quantidade total, uma vez que a empresa em assunto trabalha com locação de andaimes para outras empresas do ramo de construção civil, tendo em vista que os homens possuem maior força física o que contribui para manuseio e alcance das metas.

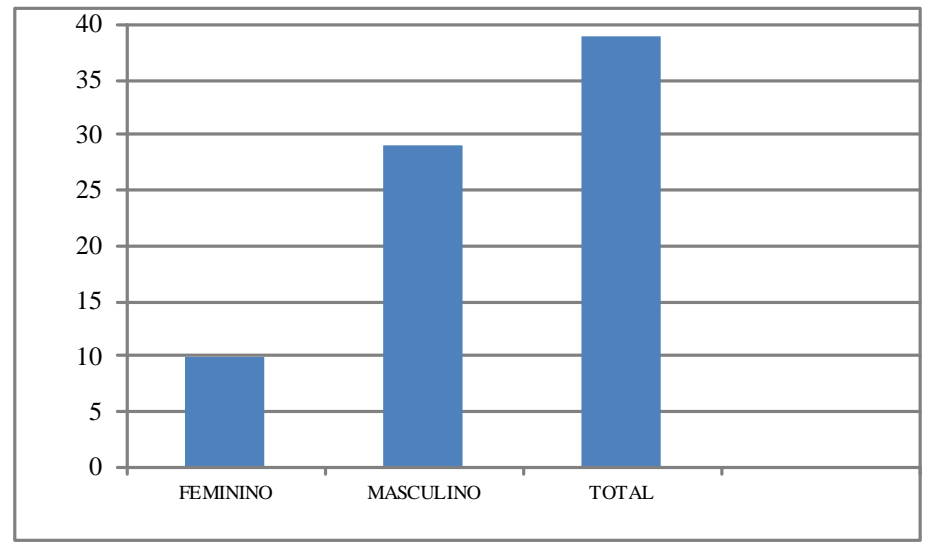

Figura 2- Distribuição dos colaboradores de acordo com o sexo.

Fonte: Autores, (2016).

Dessa forma, sugere-se que a organização mantenha essa porcentagem para que possa cumprir sempre suas metas e atender seus clientes de acordo com as especializações dos mesmos.
A figura 3 mostra que a J.B Andaimes é composta em sua maioria de colaboradores de nível operacional, pois há um número maior de colaboradores na área de produção, indicando facilidade e agilidade no procedimento produtivo da organização, nos outros setores há um número menor de colaboradores, porém com pessoas capacitadas e especializadas dando um bom direcionamento ao processo. [...] Além de uma estrutura de funções especializada, a organização precisa também de uma estrutura hierárquica para dirigir as operações dos níveis que the estão subordinados [22].

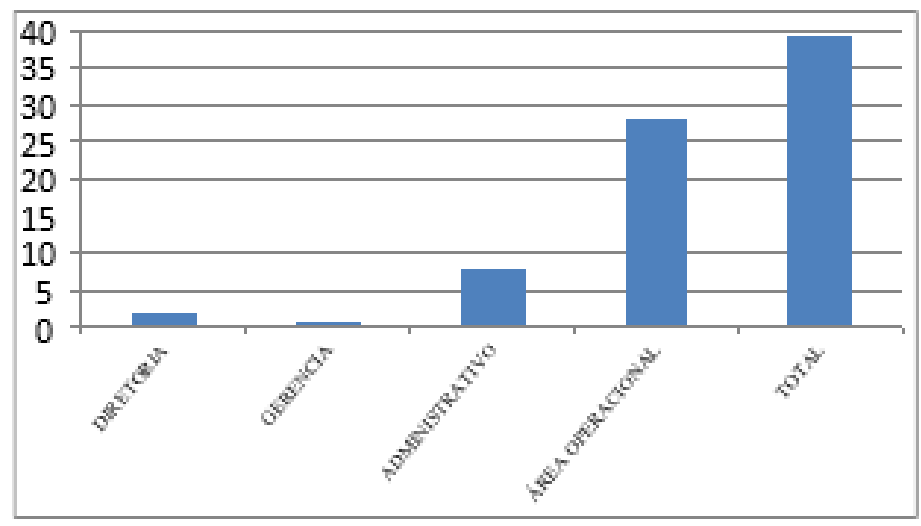

Figura 3 - Distribuição dos colaboradores de acordo com o nível hierárquico.

Fonte: Autores, (2016).

Percebe-se ainda que existam poucos gerentes para demanda de nível operacional, o que pode estar afetando negativamente o grau de controle de ações do quadro de colaboradores da organização.

\section{IV.1. GRÁFICO DAS ÁREAS CRÍTICAS - GRÁFICO RADAR}

O gráfico-radar tem como finalidade demonstrar as áreas críticas de uma organização de maneira integrada e global. O Gráfico-radar é uma forma clara e pictórica de representar o resultado da análise de cada uma das dez áreas mencionadas, [...] construído de forma circular, espalhando-se de forma radial, as dez áreas mencionadas [18].

A partir do embasamento teórico, é de suma importância que toda a empresa faça seu autodiagnostico para identificar problemas, os quais interferem no progresso da instituição. Conforme pesquisa concretizada através de questionários e análise de processos e informações fornecidas pela organização foi possível identificar vários problemas almejando alcançar soluções. A figura 4 mostra como as características estão divididas em três categorias: pontos fortes, pontos a melhorar e pontos fracos.

De acordo com o gráfico da figura 4, o atributo Meio Físico, pois está localizado na Zona 5 e indica uma grande deficiência da empresa. Utiliza-se de prédio residencial, porém 
diversos problemas persistem em sua estrutura física por não ser apropriada a área empresarial, tais como: instalação de rede elétrica, encanação de água, banheiros para clientes e estacionamento. Devido a sua estrutura física o estacionamento é pequeno e não atende a demanda dos veículos nem tampouco oferece conforto, segurança e confiabilidade aos usuários e demais interessados pelos serviços prestados pela organização, deixando a todos propensos a criminalidade.

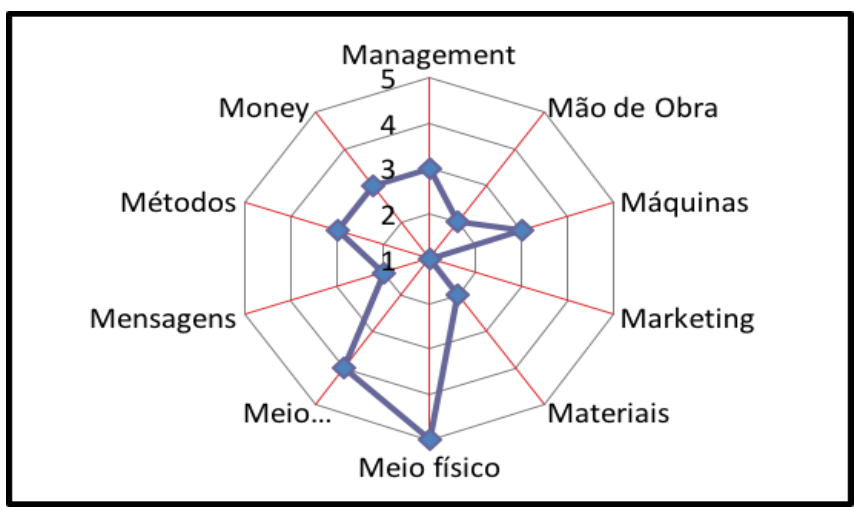

Figura 4 - Gráfico de áreas críticas (Gráfico Radar).

Fonte: Autores, (2016).

Com base nas informações coletadas durante a pesquisa alcançada foi detectada a necessidade de fazer diversas modificações do meio físico, especificadamente na área do estacionamento. Comparando os dados coletados e diante da necessidade percebida foi sugerida a ideia de um novo arranjo físico para amenizar a problemática em questão.

\section{IV.2 PROPOSTA DO NOVO ARRANJO FÍSICO DO ESTACIONAMENTO}

A figura 5 mostra o novo layout, do estacionamento que contém uma guarita, iluminação placas indicativas e sinalização o que viabiliza a todos os interessados maior confiabilidade e segurança.

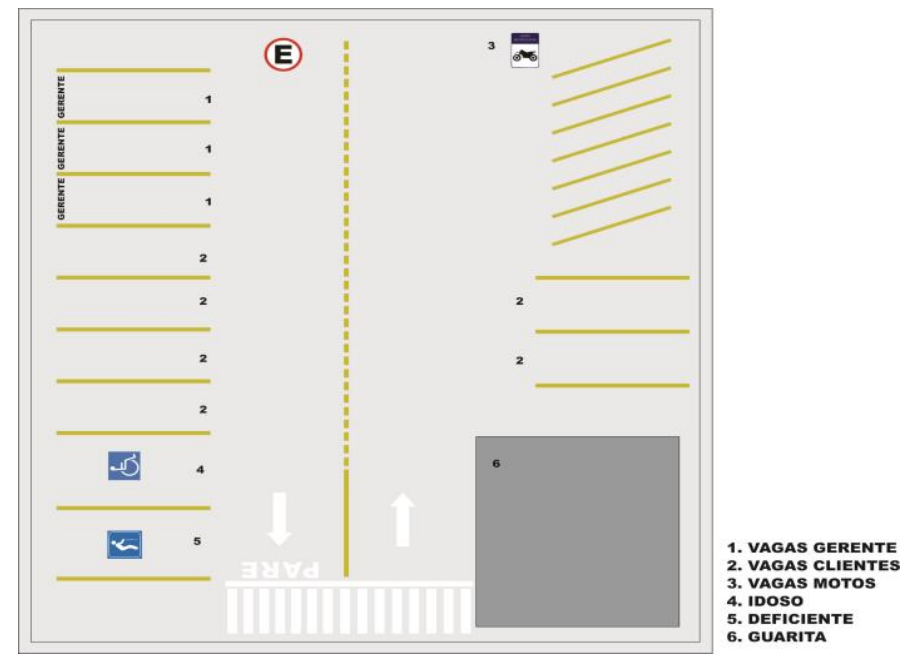

Figura 5 - Proposta do layout do estacionamento da organização.

Fonte: Autores, (2016)
A guarita é utilizada para resguardar o patrimônio da empresa assim como também a integridade física dos stakeholders. Porém para que isso ocorra é importante que esta esteja bem alocada em lugar apropriado com visibilidade da entrada. O tamanho da guarita obedece a número de pessoas que irão trabalhar permitindo a movimentação do profissional com tranquilidade de maneira que facilite o desempenho da tarefa do porteiro.

A iluminção é outro aspecto a ser avaliado no estudo do lugar. A luminosidade adequada cria um ambiente agradavel e estibulante, propicia melhores ocasiões de interesses, contentamento e bem estar dos funcionáios e clientes. A iluminação é a utilização racional dos índices de luminosidade nos ambientes de trabalho evita doenças visuais, diminui a fadiga ocular, aumenta a eficiência operacional e diminui o número de acidentes de trabalho [19].

Tem-se a iluminação natural, que é obtida da luz solar e a luminosidade sofisticada, conseguida por meio de energia elétrica. Uma boa iluminação ajuda o guarda a observar a circulação de veiculos e de pessoas que usam o estacionamento da firma.

É importante destacar que, a sinalização além de garantir segurança, serve de aviso, orientação, informação e regulação da velocidade aos condutores dos veículos, pois uma via ou estacionamento sem identificação gera sinais de perigo aos pedestres e clientes.

Faz-se necessário que a sinalização do estacionamento da organização esteja visível ao condutor do veículo ou do pedestre no período diurno e noturno de maneira a orientá-lo durante o seu percurso evitando conflito no estacionamento.

No novo layout proposto contém faixas e placas indicativas a vagas destinadas a deficiente e idoso assim como também a vagas destinadas à gerência, motociclistas, clientes e funcionários. Os fluxos de tráfego em uma via, direcionando a circulação de veículos. Regulamentam as áreas de pavimento não utilizáveis. Devem ser na cor branca quando direcionam fluxos de mesmo sentido e na proteção de estacionamento e na cor amarela quando direcionam fluxos de sentidos opostos [20].

A sinalização sugerida tem o objetivo de organizar o estacionamento provendo informações de forma nítida e objetiva para que o seu utente encontre ligeiramente o que espera. Buscando a melhoria no estacionamento, recomenda-se a implantação do novo layout proposto, o qual tem a finalidade de trazer benefícios para a empresa, tais como: segurança, organização do espaço, credibilidade, confiabilidade, motivação dos colaboradores e clientes; diminuirá o risco de assalto aos automóveis e as pessoas, acidentes de trânsito, evitando transtorno à clientela e demais interessado; aumentará a busca pelos serviços oferecidos e a imagem da organização junto aos clientes e a sociedade em geral ficarão cada vez melhor. 
Andréa de Oliveira Teixeira, et al / ITEGAM-JETIA Vol.02, № 06, pp.105-110. Junho, 2016.

\section{CONCLUSÕES}

A pesquisa objetivou propor melhorias no layout do estacionamento da empresa J.B Andaimes no segmento de locação de andaimes no ramo da construção civil na cidade de Manaus.

Para obter este objetivo, foi realizado um diagnóstico da situação atual da empresa e após os dados coletados pôde-se constatar pelo meio da análise das informações, uma deficiência no meio físico, mas especificadamente na área do estacionamento. Como toda organização necessita aumentar sua receita e manter-se competitiva junto aos seus concorrentes e buscar soluções rápidas para as necessidades de seus clientes, a proposta do novo layout do estacionamento traz a todos os interessados, espaço adequado para a acomodação de veículos, conforto, bem-estar, segurança, confiança e acima de tudo redução ao risco no tange a integridade física do público alvo assim como também da sociedade.

\section{VI .AGRADECIMENTOS}

Ao Centro Universitário do Norte (UNINORTE) e a empresa J.B Andaimes pelo apoio a realização desta pesquisa.

\section{REFERÊNCIAS BIBLIOGRÁFICAS}

[1] CLEPS, G.D.G. Estratégias de reprodução do capital e as novas especialidades urbanas: o comércio de autosserviço em Uberlândia. 2005. Tese de Doutorado, UNESP, Rio claro, 2005.

[2] CASTELLS, M. A Questão Urbana. - 3. Ed. Rio de Janeiro: Paz e terra S/A, 2006.

[3] BATESON, J.E.G. HOFFMAN, K.D. Marketing de Serviços. Porto Alegre: Bookmam, 2011.

[4] VASCONCELOS, E. A. A cidade, o transporte e o trânsito. São Paulo: Prolivros, 2005.

[5] CRUZ, M. M. L. Avaliação dos Impactos de Restrições ao trânsito de veículos. 2006. Dissertação de Mestrado Universidade de Campinas, Campinas, 2006.

[7] CASTRO, Naiara Cardoso Silva. Reestruturação do layout da área comercial da Empresa Maria Aparecida Cardoso Silva. TCC - Fundação Pedro Leopoldo - MG, 2013.

[8] SLACK, N. et al. Administração da Produção - São Paulo: Atlas, 2009.

[9] OLIVEIRA, Djalma de Pinho Rebouças de. Sistemas, organização e métodos: uma abordagem gerencial. -20. Ed. São Paulo: Atlas, 2011.

[10] DIAS, Marcos Aurélio P. Administração de materiais: uma abordagem logística. - 5. ed. - São Paulo: Atlas, 2010.

[11] MENDES, Flávia Bruno. Dissertação de Mestrado - Praças de estacionamento com estratégia para melhoria no trânsito de áreas centrais. Universidade federal de Uberlândia - Uberlândia, 2010.

[12] CURY, Antônio. Organização e Métodos: uma visão holística. - 8º ed. - São Paulo: atlas, 2012.

[13] ROCHA, Luís Oswaldo Leal da. Organização \& Métodos: Uma abordagem prática. $6^{\circ}$ ed.- São Paulo: Atlas, 1987.

[14] DENATRAN. Código Nacional de Trânsito. Departamento Nacional de Trânsito, Distrito Federal, 15 out. 2010. Disponível em: <www.denatran.gov.br/publicações/download/ctb.pdf>. Acessado em: 16 Abril. 2014.

[15] KOTLER, Philip. KELLER, Kevin Lane. Administração de Marketing: análise, planejamento, implementação e controle Tradução Ailton Bomfim Brandão - $5^{\circ}$. ed. $-9^{\circ}$. reimpr. - São Paulo: Atlas, 2011.

[16] LOVELOCK, C.; WRIGHT, L. Serviços: Marketing e Gestão. São Paulo: Saraiva 2001.

[17] CHIAVENATO, Idalberto. Introdução à Teoria Geral da Administração: uma visão abrangente da moderna administração das organizações. Rio de Janeiro: Elsevier, 2003.

[18] COSTA, Eliezer Arantes da. Gestão Estratégica: da empresa que temos para empresa que queremos. $-2^{\circ}$. ed.- São Paulo: Saraiva, 2007.

[19] MARCONI, Marina de Andrade; LAKATOS, Eva Maria. Fundamentos da metodologia científica. 7. Ed. - São Paulo: Atlas, 2010.

[20] KOTLER, Philip. KELLER, Kevin Lane. Administração de Marketing. 14 . ed. - São Paulo: Pearson Education, 2012. 